\title{
Time allocation of male and female raccoon dogs to pup rearing at the den
}

\author{
Kaarina KAUHALA, Eero HELLE and Helena PIETILÄ
}

\begin{abstract}
Kauhala K., Helle E. and Pietilä H. 1998. Time allocation of male and female raccoon dogs to pup rearing at the den. Acta Theriologica 43: 301-310.

The proportion of time that male and female raccoon dogs Nyctereutes procyonoides (Gray, 1834) spent at the den during pup rearing was studied in Finland using radiotracking. Results were compared with the behaviour of some other canids. Male raccoon dogs spent even more time at the den than females, especially during the day when males remained almost $80 \%$ of the time at the den, but females only about $60 \%$. The behaviour of males and females did not differ at night. Consequently, the behaviour of males differed at various times of day and night, but that of females did not. During the 1st month after birth pups were seldom left by themselves: during day both parents were often at the den, but at night only one of them was usually at the den. That males spend more time at the den with pups than females is common behaviour in the raccoon dog and the bat-eared fox Otocyon megalotis. These canids feed on small food items that are difficult to carry to the den, especially if food is scarce and widely distributed. Instead, the female forages and nurses the pups, and the male guards the litter. In species with larger food items, the males usually carry food to the den. When food items are very large they cannot be carried to the den, but males and other pack members feed from the carcass and regurgitate food at the den.
\end{abstract}

Finnish Game and Fisheries Research Institute, P.O. Box 6, FIN-00721 Helsinki, Finland, e-mail: kaarina.kauhala@rktl.fi (KK, EH); Department of Zoology, University of Oulu, FIN-90570 Oulu, Finland (HP)

Key words: Nyctereutes procyonoides, pup rearing, parental behaviour, canids

\section{Introduction}

Canids are usually monogamous, and the basic social unit is the mated pair (Kleiman and Eisenberg 1973, Kleiman 1977). In most canids, the male and sometimes also other group members ('helpers') participate in pup rearing (Kleiman and Eisenberg 1973): they carry or regurgitate food for the female and pups in the den (Moehlman 1986, 1992). This male care is closely associated with monogamy (Clutton-Brock 1991).

According to Moehlman (1986) medium-sized canids are strictly monogamous, but small canids show a tendency toward polygyny and large canids live in packs and show a tendency toward polyandry. The maned wolf Chrysocyon brachyurus is, however, a large canid that feeds on small prey and neither lives in packs nor 
is polyandrous (Krieg 1948, Silveira 1968, Moehlman 1986). Diet, especially prey size, and hunting strategy may thus be more important than body size in determining group size, mating system and parental care among canids (see also Geffen et al. 1996, Kauhala 1996).

The raccoon dog Nyctereutes procyonoides (Gray, 1834) is a small, monogamous canid that was introduced into Europe from SE Russia (Lavrov 1971, Helle and Kauhala 1991, Kauhala et al. 1993a, Kauhala and Helle 1994). Ikeda (1983) and Yamamoto (1987) showed that the male raccoon dog participated in pup rearing and even spent more time with the pups than the female. These Japanese studies were, however, conducted in small enclosures and concerned the Japanese subspecies of the raccoon dog ( $N$. p. viverrinus). The Japanese raccoon dog, also called tanuki, is, however, rather different from the subspecies $N$. p. ussuriensis which was introduced into Europe. Tanuki is adapted to a mild marine climate, is smaller, and not dormant in winter, and even its chromosome number differs from that of N. p. ussuriensis (Mäkinen et al. 1986). Differences may thus also occur in behaviour, such as pup rearing. Furthermore, it is not clear whether tanuki is strictly monogamous or not (Ward and Wurster-Hill 1990).

The aim of the present study was to examine the proportion of time female and male raccoon dogs ( $N$. p. ussuriensis) spent at the den during pup rearing in the wild and to compare their behaviour with that of some other canids. The time spent at the den was here interpreted as showing parental care, ie the time parents spent with the pups either nursing or guarding and warming them, because during summer raccoon dogs without pups use dens only occasionally.

\section{Material and methods}

Five pairs of raccoon dogs were radio-tracked in the Evo research area, southern Finland, during 1991-1996. Since raccoon dogs usually give birth during the latter half of May in southern Finland, radio-tracking was begun in mid-May and continued for about 6 weeks. Details of location and description of the study area are given in Kauhala et al. (1993a).

The raccoon dogs were located every $15 \mathrm{~min}$ both during day and at night. In 1991 we radiotracked a raccoon dog pair for one $24 \mathrm{~h}$ period each week. In 1994-1996 radio-tracking was performed over shorter periods (mean $30 \mathrm{~h}$ per week): 1 pair in 1994 was radio-tracked for $123 \mathrm{~h}, 1$ pair in 1995 for $184 \mathrm{~h}$, pair1 in 1996 for $218 \mathrm{~h}$ and pair2 in 1996 for $190 \mathrm{~h}$. Since 1 location event requires about $5 \mathrm{~min}$, the true time between 2 successive locations was only about $10 \mathrm{~min}$. Thus, if an animal was located at the den or in the immediate area of the den several times in succession, it was very unlikely that it had been far from the den between locations. We thus interpreted that each location event corresponded a 15-min time period and that our data resulted in a true time budget.

Due to possible location error (see Kauhala et al. 1993a) we concluded that the animal was at the den if the bearing gave the direction to the den within $\pm 100 \mathrm{~m}$. Besides, our own observations suggest that when the parents are guarding the pups at the den, they may move a little around the den. We thus decided that when the bearing gave the direction to the den within $\pm 100 \mathrm{~m}$, the animal was guarding the pups at the den. In the following, 'at the den' thus means in the den or in the immediate area of the den.

We calculated the percentage of time that either the male, female or both remained at the den, and the percentage of time the pups were left alone during 5 successive weeks after birth. We 
supposed that parturition took place within a few days after the pair settled to a den. In most cases we could verify the approximate time of parturition afterwards when we saw pups with their parents after they had left the den. We first compared the behaviour of males and females before and after the pups were born and during day and at night (paired $t$-test). Day was defined as from 06.00 to 22.00 and night from 22.00 to 06.00 . We also examined the behaviour of the raccoon dogs in more detail at various times of day and night by dividing the $24 \mathrm{~h}$ into 4 - $\mathrm{h}$ periods (Friedman 2-way analysis of variance).

\section{Results}

Radio-tracking data indicated that the behaviour of both males and females changed when the pups were born (Fig. 1). Both parents spent more time at the den after parturition than before parturition (paired $t$-test: female, day $t=4.00$, $p=0.016$, night $t=3.75, p=0.020$; male, day $t=4.25, p=0.013$, night $t=4.38$,

Fig. 1. Mean proportion of time the male

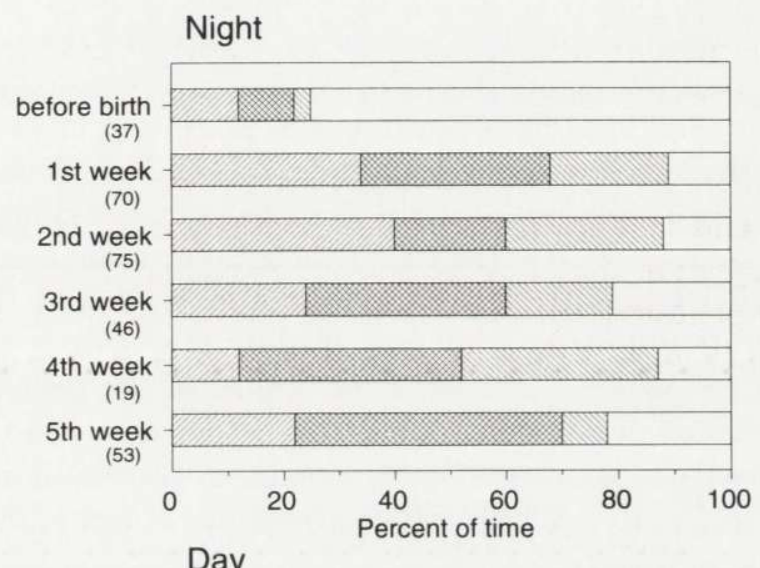

Day

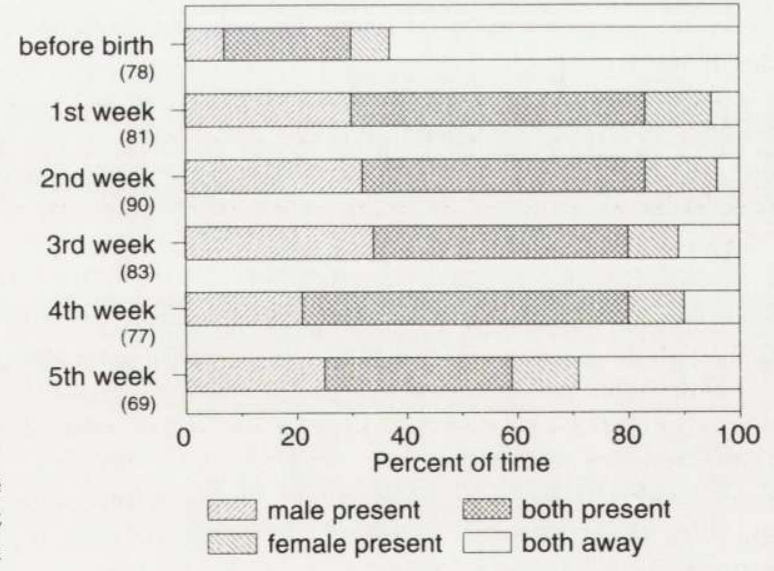
at the den or away from the den 1 week before and 5 weeks after parturition. The number of hours radio-tracked is given in parentheses. 


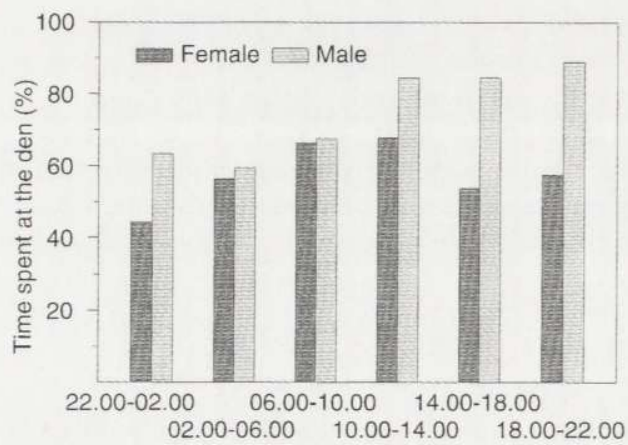

Fig. 2. Mean proportion of time the male and female raccoon dogs remained at the den during different periods of night and day. Five pairs were examined during the first month after parturition.

$p=0.012$ ). Prior to parturition parents travelled together and spent simultaneously most of the time away from the den (mean at night $77 \%$ and during day 63\%) (Fig. 1). During their 1st month pups were left alone, ie both parents were away for only $15 \%$ (range for 5 pairs $7-34 \%$ ) of the time at night, and $7 \%$ (range 2-12\%) during day (Fig. 1).

During the 1st-5th weeks after the pups were born males spent more time at the den than females during day (mean for males $77 \%$, for females $60 \%, t=3.2$, $p=0.032$ ), but at night their behaviour did not differ (mean for males $61 \%$, for females $50 \%, t=1.6, \mathrm{~ns}$ ), although variation occurred between different pairs/years. Consequently, the behaviour of males during the first month after pups were born differed during day and at night $(t=3.48, p=0.025)$, but that of females did not $(t=1.92, \mathrm{~ns})$. Males spent $>80 \%$ of the time at the den from 10.00 to 22.00 and about $60 \%$ of the time from 22.00 to 10.00 (Fig. 2, difference between the 4-h periods was significant, Friedman test statistic $=13.1, p=0.022$ ). The behaviour of females did not differ at various times of day or night (Friedman test statistic $=8.57, \mathrm{~ns})$.

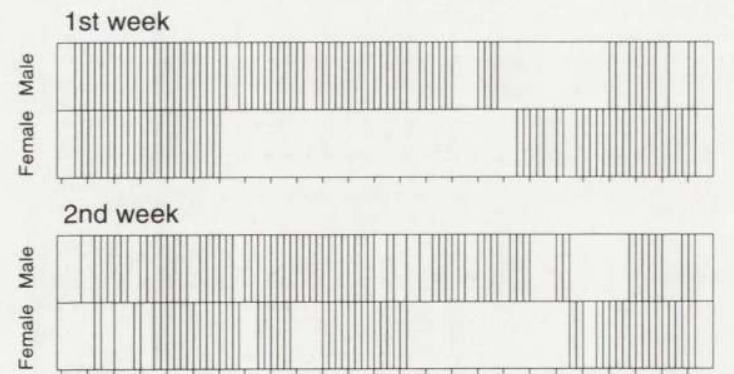

3rd week

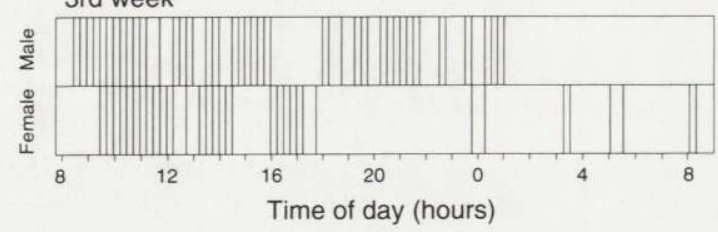

Fig. 3. The time spent at the den by the male and female raccoon dogs during the 1st-3rd weeks after parturition in summer 1991. Each bar indicates 1 observation which corresponds to $15 \mathrm{~min}$. 
At night, one of the parents was usually at the den; when one entered the other left. This was very clear in 1991 when we were able to radio-track the raccoon dogs for the entire 24-h period each week (Fig. 3).

\section{Discussion}

\section{Behaviour of raccoon dogs}

Raccoon dogs use a den when they have young pups and during winter sleep. At other times of the year the den is used only occasionally. This was evident also in the present study; the parents settled in a den only when the pups were born. After parturition the parents spent much time at the den; pups were seldom left alone during the 1st month after birth. Also Ikeda (1983) and Yamamoto (1987) found that pups were not usually left alone during the 1st weeks after birth.

Males spent even more time at the den with the pups than females. This confirmed the results obtained from Japanese studies (Ikeda 1983, Yamamoto 1987). Males spent very much time at the den especially during day when females were long periods away. The energy needs of nursing females are high; they forage both during day and at night to obtain enough energy for milk production. Males also forage at night, but because they do not need so much food as females, they stay at the den guarding and warming the pups during day. The raccoon dog's den is usually an old badger or fox den under big rocks. The den is very cold even in summer, and young pups must be warmed. Raccoon dog pups are also very vulnerable to predation and must be guarded against predators. The fact that the male is 'babysitting' makes it possible for the female to use long periods for foraging. At night, one of the parents was usually at the den; when one entered the other left. This also happened in an enclosure where we video recorded one pair in summer 1996.

In the enclosure, the pups were seen to eat solid food for the first time when they were 26 days old. We did not see the parents carry food to the den or regurgitate food for the pups. Thus, we only saw the female nursing the young pups, which also suggests that pups are fed with milk only and the female has to be away from the den for long periods to get enough food. Also according to Yamamoto (1987) the male has not been observed to regurgitate food for pups but he warms and guards the pups at the den. According to Ikeda (1983) the male may, however, carry food to the female, especially during the 1st days after delivery, but this was not confirmed in the present study.

The captive female (observed in an enclosure of size $3 \times 10 \mathrm{~m}$ ) spent some time lying far from the den (>5 m) from the 2 nd week onwards, but the male very seldom rested outside the den (Fig. 4). During the 1st week none of the parents rested outside the den. When the female was resting far from the den, the male was usually with the pups (93\% of the time). These observations confirm our results from the wild; the male 'babysits' more than the female. 


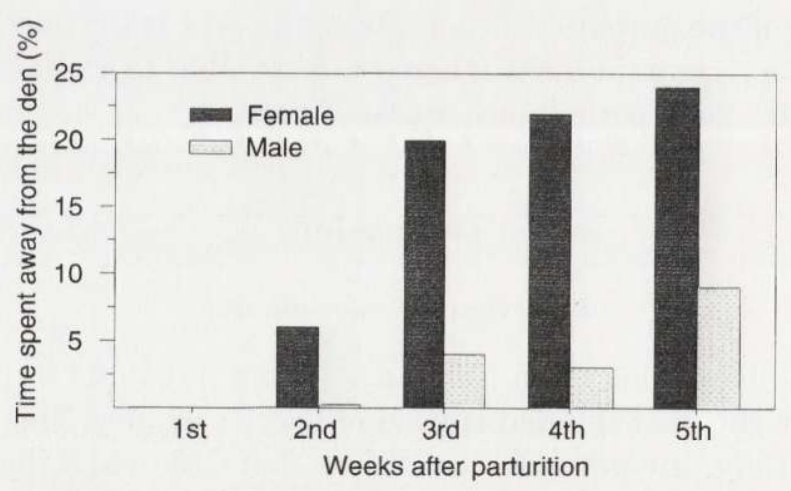

Fig. 4. Percent of time the male and female of one raccoon dog pair spent resting away from the den during pup rearing in an enclosure.

In the enclosure, pups left the den for the 1st time at 20 days of age. The male was also seen to carry the pups back to the den when the latter were 21 days old and had left the den by themselves. This also points to the conclusion that the male mainly guards the pups.

\section{Comparison with some other canids}

Among canids, the size of the food items may be an important factor affecting the division of labour between sexes in pup rearing. Carrying food to the den is not energetically efficient when food items are very small, as in the case of the raccoon dog (Yamamoto 1987, Kauhala et al. 1993b, Sasaki and Kawabata 1994). Instead, pups are fed only with milk during the first weeks until they begin to forage for themselves. The male warms and guards the pups while the female forages. The bat-eared fox Otocyon megalotis is another small canid that feeds on small food items, mainly insects (Nel 1978, Lamprecht 1979, Malcolm 1986, Nel and Mackie 1990). It is usually monogamous (Lamprecht 1979, Nel et al. 1984, Mackie and Nel 1989) and employs a strategy similar to that of the raccoon dog: the male guards the litter while the female forages. The female is usually away for about 9.5-10 h while the male forages only $3-4 \mathrm{~h}$ and always close to the den (Nel 1978, Malcolm 1986, Mackie and Nel 1989). The female also rests far from the den more often than the male, probably because she needs more rest.

Blanford's fox Vulpes cana is a very small canid that also feeds on insects (Geffen and Macdonald 1992). They have not been seen to carry food to the den, but it appears that the pups are entirely dependent on milk until they start to forage for themselves (Geffen and Macdonald 1992). This small monogamous fox thus resembles the raccoon dog and bat-eared fox, but unfortunately the role of the male in pup care is not clear.

Regurgitating food for the pups may be one solution to the problem of small food items. If a species adopts this strategy, the female may remain with the pups 
while the male forages and carries food to the den in his stomach. The maned wolf is a large, omnivorous canid that feeds mainly on small food items, such as fruits, small mammals, birds, and insects (Dietz 1984). It is supposed to be monogamous, and males have been observed to participate in pup care and regurgitate food for the pups in captivity (Rasmussen and Tilson 1984, Sheldon 1992).

Also male bat-eared foxes may rarely regurgitate food for pups (Lamprecht 1979). In contrast to the raccoon dog, food of the bat-eared fox may be very abundant, and if the male locates a rich food source (eg termites) near the den, he may quickly forage sufficiently to return to the den and regurgitate food. Male raccoon dogs are usually not able to find food as quickly, but may spend many hours gathering food; thus the male would at least partly digest the food himself before returning to the den.

The male usually carries food for the female and young pups when food items are medium-sized. The red fox Vulpes vulpes has adopted this strategy (Sheldon 1949, Storm 1965, Macdonald 1977, 1979, Sheldon 1992). When the pups are older they can be left alone, and both parents bring them food (Macdonald and Barrett 1993). The red fox lives in similar habitats as the raccoon dog in Finland, but is able to kill larger prey than the raccoon dog (Hersteinsson and Macdonald 1982, Sheldon 1992, Kauhala et al. 1998), and this prey is easy to carry to the den. In fact, red foxes carry large prey to the den while they might eat small prey themselves (Lindström 1994). These food remains are often found at fox dens (Macdonald 1987), but very seldom at raccoon dog dens (K. Kauhala, pers. obs.).

If food items are very large parents are not able to carry food to the den for the pups. For example, the grey wolf Canis lupus, African wild dog Lycaon pictus and the bush dog Speothos venaticus hunt large animals such as the moose, gazelles, or other antelopes (Estes and Goddard 1967, Pienaar 1969, Mech 1974, 1975, Biben 1982). The male and other pack members consume the carcass and regurgitate food for the female and pups (Kühme 1965, Mech 1970, Fox 1971, Malcolm and Marten 1982, Estes 1991), although small parts of the carcass may sometimes be carried to the pups (Malcolm and Marten 1982).

\section{Conclusions}

Although some differences exist between the Finnish and Japanese raccoon dogs, their behaviour during pup rearing seems to be similar. Both eat small food items and the male babysits while the female is foraging.

The size of the food items has most probably contributed to the evolution of the division of labour between the sexes among canids. Very small food items are difficult to carry to the den, especially if food is scarce and widely distributed. Males thus guard the litter while the females forage, and the pups are fed entirely with milk until they begin to forage for themselves. If food sources are rich and 
near the den, food can sometimes be carried in the stomach and regurgitated for the pups. In the case of very large food items, food can also be carried in stomachs and regurgitated at the den. If food items are medium-sized they can be easily carried to the den, usually by the males, while the female is at the den with the pups.

The exceptional division of labour between male and female raccoon dogs is thus due to their diet, which consists mainly of small food items, and widely distributed food sources.

Acknowledgements: We are very grateful to S. Airaksinen, H. \& K. Koivunen, R. Laaja, P. Laukkanen, E. Murtomäki, and M. Rehell for radio-tracking, and to R. Koivunen for helping to video-record raccoon dogs. We also thank $\mathrm{H}$. Pöysä for giving advice in statistics, and $\mathrm{S}$. Puonti for helping to catch the raccoon dogs with his dogs. The study was supported by the Academy of Finland (Research Council for Agriculture and Forestry).

\section{References}

Biben M. 1982. Ontogeny of social behaviour related to feeding in the crab-eating fox (Cerdocyon thous) and the bush dog (Speothos venaticus). Journal of Zoology, London 196: 207-216.

Clutton-Brock T. H. 1991. The evolution of parental care. Princeton University Press, Princeton: $1-352$.

Dietz J. M. 1984. Ecology and social organization of the maned wolf (Chrysocyon brachyurus). Smithsonian Contributions to Zoology 392: 1-51.

Estes R. D. and Goddard J. 1967. Prey selection and hunting behavior of the African wild dog. The Journal of Wildlife Management 31: 52-70.

Estes R. D. 1991. The Behavior Guide to African Mammals, Including Hoofed Mammals, Carnivores, Primates. The University of California Press, Berkeley: 1-611.

Fox M. W. 1971. Behavior of wolves, dogs and related canids. Robert E. Krieger Publishing company, Inc., Malabar, Florida: 1-220.

Geffen E. and Macdonald D. W. 1992. Small size and monogamy: spatial organization of Blanford's foxes, Vulpes cana. Animal Behavior 44: 1123-1130.

Geffen E., Gompper M., Gittleman J. L., Luth H.-K., Macdonald D. W. and Wayne R. K. 1996. Size, life history traits, and social organization in the Canidae: a reevaluation. The American Naturalist 147: $140-160$.

Helle E. and Kauhala K. 1991. Distribution history and present status of the raccoon dog in Finland. Holarctic Ecology 14: 278-286.

Hersteinsson P. and Macdonald D. W. 1982. Some comparisons between red and arctic foxes, Vulpes vulpes and Alopex lagopus, as revealed by radio tracking. Symposia of the Zoological Society of London 49: 259-289.

Ikeda H. 1983. Development of young and parental care of raccoon dog Nyctereutes procyonoides viverrinus Temmick, in captivity. Journal of the Mammalogical Society of Japan 9: 229-235.

Kauhala K. 1996. Reproductive strategies of the raccoon dog and the red fox in Finland. Acta Theriologica 41: 51-58.

Kauhala K. and Helle E. 1994. Home ranges and monogamy of the raccoon dog in southern Finland. Suomen Riista 40: 32-41. [In Finnish with English summary]

Kauhala K., Helle E. and Taskinen K. 1993a. Home range of the raccoon dog (Nyctereutes procyonoides) in southern Finland. Journal of Zoology, London 231: 95-106.

Kauhala K., Kaunisto M. and Helle E. 1993b. Diet of the raccoon dog, Nyctereutes procyonoides, in Finland. Zeitschrift für Säugetierkunde 58: 129-136. 
Kauhala K., Laukkanen P. and von Rége I. 1998. Summer food composition and food niche overlap of the raccoon dog, red fox and badger in Finland. Ecography (in press).

Kleiman D. G. 1977. Monogamy in mammals. The Quarterly Review of Biology 52: 39-69.

Kleiman D. G. and Eisenberg J. F. 1973. Comparisons of canid and felid social systems from an evolutionary perspective. Animal Behaviour 21: 637-659.

Krieg H. 1948. Zwischen Anden und Atlantik. Reisen eines Biologen in Südamerika. C. Hanser, Munich: 1-481.

Kühme W. 1965. Communal food distribution and division of labour in African hunting dogs. Nature (London) 205: 443-444.

Lamprecht J. 1979. Field observations on the behaviour and social system of the bat-eared fox Otocyon megalotis Desmarest. Zeitschrift für Tierpsychologie 49: 260-284.

Lavrov N. P. 1971. [The results of introductions of the raccoon dog (Nyctereutes procyonoides) in different provinces in the USSR.] Trudy Kafedry Biologii MGZPI 29: 101-160. [In Russian]

Lindström E. R. 1994. Large prey for small cubs - on crucial resources of a boreal red fox population. Ecography 17: 17-22.

Macdonald D. W. 1979. Helpers in fox society. Nature (London) 282: 69-71.

Macdonald D. W. 1987. Running with the fox. Unwin Hyman, London: 1-224.

Macdonald D. W. and Barrett P. 1993. Mammals of Britain and Europe. Harper Collins Publishers, London: 1-312.

Mackie A. J. and Nel J. A. J. 1989. Habitat selection, home range use, and group size of bat-eared foxes in the Orange Free State. South African Journal of Wildlife Research 19: 135-139.

Malcolm J. R. 1986. Socio-ecology of bat-eared foxes (Otocyon megalotis). Journal of Zoology, London 208: 457-467.

Malcolm J. R. and Marten K. 1982. Natural selection and the communal rearing of pups in African wild dogs (Lycaon pictus). Behavioral Ecology and Sociobiology 10: 1-13.

Mech L. D. 1970. The Wolf: Ecology and Behavior of an Endangered Species. Natural History Press, New York: 1-384.

Mech L. D. 1974. Canis lupus. Mammalian Species 37: 1-6.

Mech L. D. 1975. The status of the wolf in the United States, 1973. [In: Wolves: Proceedings of the First Working Meeting of the Wolf Specialists and of the First International Conference on Conservation of the Wolf. D. H. Pimlott, ed]. IUCN Publ. New Ser. Suppl. Paper No. 43: 83-88.

Moehlman P. D. 1986. Ecology of cooperation in canids. [In: Ecological Aspects of Social Evolution: Birds and mammals. D. I. Rubenstein and R. W. Wrangham, eds]. Princeton University Press, Princeton: $64-86$.

Moehlman P. D. 1992. Introduction. [In: Wild dogs: The Natural History of the Nondomestic Canidae. J. W. Sheldon]. Academic Press, Inc., San Diego: 1-3.

Mäkinen A., Kuokkanen M. T. and Valtonen M. 1986. A chromosome-banding study in the Finnish and Japanese raccoon dog. Hereditas 105: 97-105.

Nel J. A. J. 1978. Notes on the food and foraging behaviour of the bat-eared fox, Otocyon megalotis. Bulletin Carnegie Museum of Natural History 6: 132-137.

Nel J. A. J. and Mackie A. J. 1990. Food and foraging behaviour of bat-eared foxes in the south-eastern Orange Free State. South African Journal of Wildlife Research 20: 162-166.

Nel J. A. J., Mills M. G. L. and Van Aarde R. J. 1984. Fluctuating group size in bat-eared foxes (Otocyon m. megalotis) in the south-western Kalahari. Journal of Zoology, London 203: 294-298.

Pienaar U., de Van 1969. Predator-prey relationships amonst the larger mammals of the Kruger National Park. Koedoe 12: 108-176.

Rasmussen J. L. and Tilson R. L. 1984. Food provisioning by adult maned wolfes (Chrysocyon brachyurus). Zeitschrift für Tierpsychologie 49: 260-284.

Sasaki H. and Kawabata M. 1994. Food habits of the raccoon dog Nyctereutes procyonoides viverrinus in a mountainous area of Japan. Journal of the Mammalogical Society of Japan 19: 1-8. 
Sheldon W. G. 1949. Reproductive behaviour of foxes in New York State. Journal of Mammalogy 30: 236-246.

Sheldon J. W. 1992. Wild dogs: The Natural History of the Nondomestic Canidae. Academic Press, Inc., San Diego: 1-248.

Silveira E. K. P., da 1968. Notes on the care and breeding of the maned wolf Chrysocyon brachyurus at Brasilia Zoo. International Zoo Yearbook 8: 21-23.

Storm G. L. 1965. Movements and activities of foxes as determined by radio-tracking. The Journal of Wildlife Management 29: 1-13.

Ward O. G. and Wurster-Hill D. H. 1990. Nyctereutes procyonoides. Mammalian Species 358: 1-5.

Yamamoto I. 1987. Male parental care in the raccoon dog Nyctereutes procyonoides during the early rearing period. [In: Animal Societies: Theories and Facts. Y. Ito, J. L. Brown and J. Kikkawa, eds]. Japan Scientific Societies Press, Tokyo: 189-195.

Received 24 March 1997, accepted 13 May 1998. 